\title{
Correction to: Ancestral Folate Promotes Neuronal Regeneration in Serial Generations of Progeny
}

\author{
Nirav J. Patel ${ }^{1} \cdot$ Kirk J. Hogan $^{2} \cdot$ Elias Rizk $^{1} \cdot$ Krista Stewart $^{1} \cdot$ Andy Madrid $^{1} \cdot$ Sivan Vadakkadath Meethal $^{1}$. \\ Reid Alisch ${ }^{1}$. Laura Borth ${ }^{1}$ - Ligia A. Papale ${ }^{1}$. Solomon Ondoma ${ }^{1} \cdot$ Logan R. Gorges $^{1} \cdot$ Kara Weber $^{1}$. \\ Wendell Lake ${ }^{1}$ - Andrew Bauer ${ }^{1}$. Nithya Hariharan ${ }^{1}$. Thomas Kuehn ${ }^{1}$ - Thomas Cook ${ }^{3}$. Sunduz Keles ${ }^{3,4}$. \\ Michael A. Newton ${ }^{3,4} \cdot$ Bermans J. Iskandar ${ }^{1}$ (D)
}

Published online: 30 January 2020

(C) Springer Science+Business Media, LLC, part of Springer Nature 2020

\section{Correction to: Mol Neurobiol}

https://doi.org/10.1007/s12035-019-01812-5

The original version of this article unfortunately contained error in Figure 4a to where some of the text was overlapping.

The correct Figure $4 \mathrm{a}$ is hereby published.

The online version of the original article can be found at https://doi.org/ 10.1007/s12035-019-01812-5

Bermans J. Iskandar

Iskandar@neurosurgery.wisc.edu

1 Department of Neurological Surgery, University of Wisconsin, 600 Highland Avenue, K4/832, Madison, WI 53792, USA

2 Department of Anesthesiology, University of Wisconsin, Madison, WI, USA

3 Department of Biostatistics and Medical Informatics, University of Wisconsin, Madison, WI, USA

4 Department of Statistics, University of Wisconsin, Madison, WI, USA 
A

F3 Generation from F0-Treated Rats (IP)
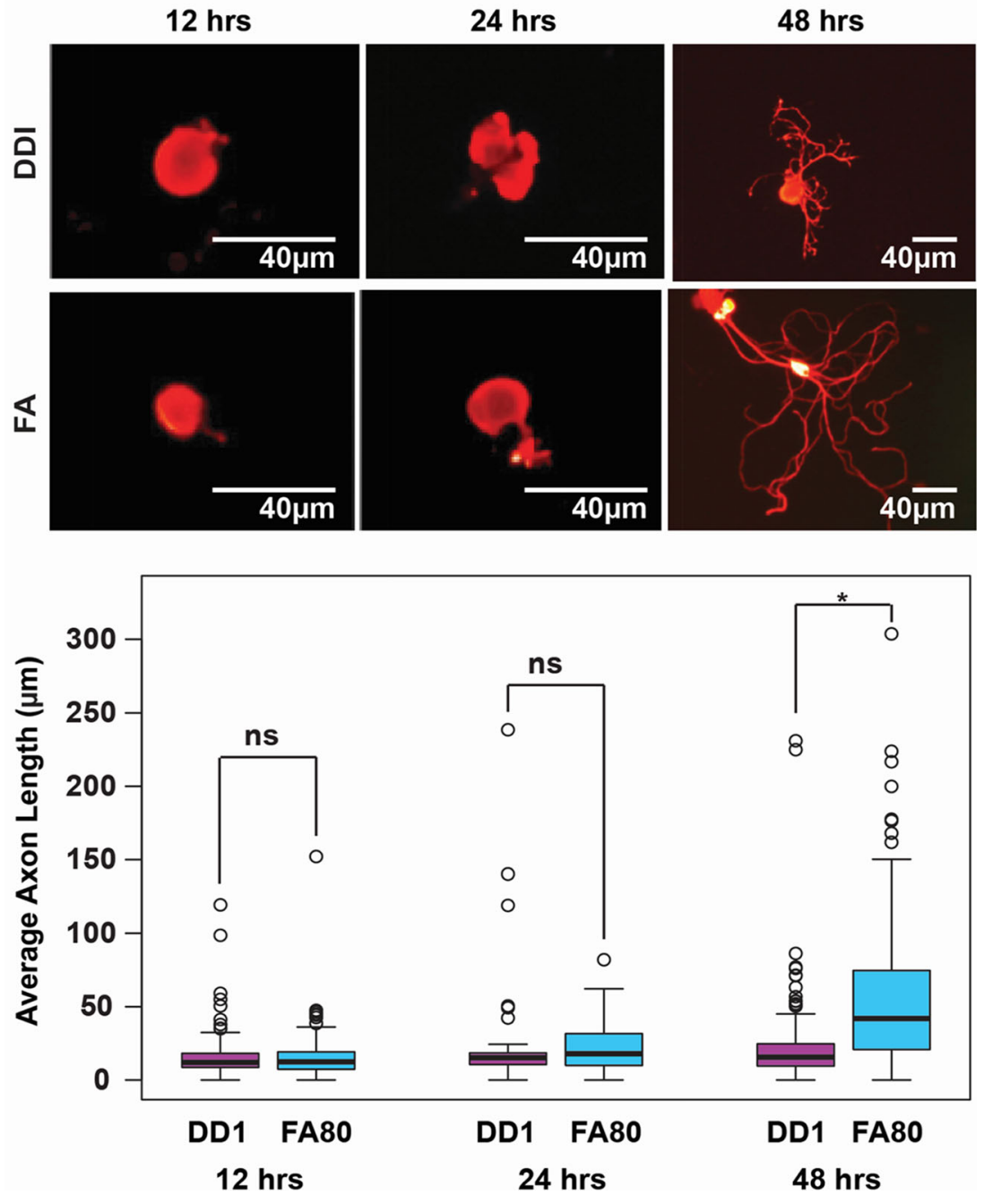

The original article has been corrected.

Publisher's Note Springer Nature remains neutral with regard to jurisdictional claims in published maps and institutional affiliations. 